\title{
Evaluation of the efficacy and reproducibility of cholangiopancreatography by magnetic resonance for detecting biliary complications following orthotopic liver transplantation ${ }^{1}$
}

\author{
Estudo da eficácia e da reprodutibilidade da colangiopancreatografia por ressonância magnética \\ na detecção das complicações biliares pós-transplantes hepáticos
}

\begin{abstract}
Marcelo Moura Linhares ${ }^{\mathrm{I}}$, Rafael Darahen de Souza Coelho"I , Jacob Szejnfeld ${ }^{\mathrm{III}}$, Susan Menasce Goldman ${ }^{\mathrm{IV}}$, Adriano Miziara Gonzalez $^{\mathrm{V}}$, Denis Szejnfeld ${ }^{\mathrm{VI}}$, Carla Matos ${ }^{\mathrm{VII}}$, Alcides Salzedas ${ }^{\mathrm{VIII}}$, Alberto Goldenberg ${ }^{\mathrm{IX}}$, Gaspar Jesus Lopes-Filho ${ }^{\mathrm{X}}$, Delcio Matos ${ }^{\mathrm{XI}}$
\end{abstract}

${ }^{I} \mathrm{PhD}$, Affiliated Professor, Department of Surgery, UNIFESP, São Paulo, Brazil.

II $\mathrm{PhD}$, Department of Image Diagnostic, UNIFESP, São Paulo, Brazil.

${ }^{\text {III }} \mathrm{PhD}$, Associate Professor, Department of Image Diagnostic, UNIFESP, São Paulo, Brazil.

Iv PhD, Affiliated Professor, Department of Image Diagnostic, UNIFESP, São Paulo, Brazil.

${ }^{v}$ PhD, Affiliated Professor, Department of Surgery, UNIFESP, São Paulo, Brazil.

VI Volunter, Department of Image Diagnostic, UNIFESP, São Paulo, Brazil.

${ }^{\text {VII }} \mathrm{PhD}$, Department of Medicine, UNIFESP, São Paulo, Brazil.

VIII PhD, Division of Liver Transplantation, Department of Surgery, UNIFESP, São Paulo, Brazil.

Ix $\mathrm{PhD}$, Associate Professor, Department of Surgery, UNIFESP, São Paulo, Brazil.

x PhD, Chairman, Division of Liver Transplantation, Department of Surgery, UNIFESP, São Paulo, Brazil.

${ }^{\mathrm{xI}} \mathrm{PhD}$, Chairman, Division of Surgical Gastroenterology, Department of Surgery, UNIFESP, São Paulo, Brazil.

\begin{abstract}
Purpose: To evaluate the accuracy and reproducibility of magnetic resonance cholangiopancreatography (MRCP) in the detection of biliary complications in liver transplanted patients. Methods: A study was conducted, with blinded review of $28 \mathrm{MRCP}$ exams of 24 patients submitted to liver transplantation. The images were reviewed by two independent observers, at two different moments, regarding the degree of biliary tree visualization and the presence or absence of biliary complications. The MRCP results were compared, when negative, to at least 3 months of clinical and biochemical follow-up, and when positive, to the findings at surgery or endoscopic retrograde cholangiopancreatography (ERCP). Results: The degree of intrahepatic biliary tree visualization was considered good or excellent in $78.6 \%$ and $82.1 \%$ of the exams by the two observers and visualization of the donor duct, recipient duct and biliary anastomosis was considered good or excellent in 100\% of the exams, by both observers. Six biliary complications were detected (21.4\%), all of them anastomotic strictures. Intra and interobserver agreement were substantial or almost perfect (kappa $k$ values of 0.611 to 0.804 ) for the visualization of the biliary tree and almost perfect ( $k$ values of 0.900 to 1.000) for the detection of biliary complications. MRCP achieved $100 \%$ sensitivity, $95.45 \%$ specificity, $85.7 \%$ positive predictive value and $100 \%$ negative predictive value for the detection of biliary complications. Conclusions: MRCP is an accurate examination for the detection of biliary complications after orthotopic liver transplantation and it is a highly reproducible method in the evaluation of the biliary tree of liver transplanted patients. Key words: Liver Transplantation. Magnetic Resonance Imaging. Bile Ducts. Cholangiography.
\end{abstract}

\section{RESUMO}

Objetivo: Medir a acurácia e reprodutibilidade da colangiopancreatografia por ressonância magnética (CPRM) na avaliação da visibilização de complicações biliares em pacientes submetidos a transplantes hepáticos ortotópicos. Métodos: Realizado estudo retrospectivo de 28 exames de CPRM de 24 pacientes submetidos a transplantes hepáticos. Os exames foram interpretados por dois observadores independentes, em dois momentos distintos, quanto ao grau de visibilização das estruturas estudadas e quanto à presença ou ausência de alterações nas vias biliares. Os resultados da CPRM foram comparados, nos casos de CPRM negativa, à evolução clínico-laboratorial por pelo menos 3 meses e, nos casos de CPRM alterada, aos achados de colangiopancreatografia retrógrada endoscópica (CPRE) e cirurgia, quando indicados. Resultados: A visibilização das vias biliares intra-hepáticas foi considerada boa ou excelente em 78,6\% e 82,1\% dos exames pelos dois observadores. A visibilização da via biliar extra-hepática do doador e do receptor, bem como da anastomose biliar, foi considerada boa ou excelente em 100\% dos casos por ambos os observadores. Foram detectadas seis complicações biliares (21,4\% dos casos), todas elas estenoses anastomóticas. A concordância intra e intra-observador foi substancial ou quase perfeita (índices de kappa- $k$ de 0,611 a 0,804$)$ para a visualização das estruturas estudadas e quase perfeita $(k$ de 0,900 a 1,000$)$ para a detecção das complicações biliares. A CPRM apresentou sensibilidade de $100 \%$, especificidade de $95,45 \%$, valor preditivo positivo de $85,7 \%$ e valor preditivo negativo de $100 \%$ para a detecção de complicações biliares. Conclusões: A colangiopancreatografia por ressonância magnética (CPRM) é um exame acurado para a detecção de complicações biliares em pacientes submetidos a transplantes hepáticos ortotópicos por CPRM. Este exame configura-se como um método eficiente e altamente reprodutível para detecção de complicações biliares pós-transplantes hepáticos ortotópicos.

Descritores: Transplante de Fígado. Imagem por Ressonância Magnética. Ductos Biliares. Colangiografia. 


\section{Introduction}

Despite advances in surgical techniques, graft preservation methods, immunosuppression and intensive care, postoperative complications following liver transplantation are still common. Among these, biliary complications have been highlighted, with incidence rates ranging from 1 to $50 \%$ in different published series, and mostly between 10 and $30 \%{ }^{1-16}$. The postoperative period following orthotopic liver transplantation (OLT) is a challenge for transplantation teams, because the clinical and laboratory manifestations of the various potential complications from this procedure present a high degree of overlap. This creates difficulties in making specific diagnoses and thus in determining the respective therapeutic approach.

Intensive control through laboratory tests allows early detection of graft dysfunctions. However, such abnormalities may be very unspecific and subtle. High levels of liver enzymes, canaliculi and bilirubin may result from a graft preservation lesion (with a self-limiting course), acute or chronic cell rejection, ischemic lesions, cholangitis, viral infection, drug toxicity or bile duct obstruction processes. Histological analysis of percutaneous biopsy products is sometimes inconclusive and may show patterns that are common to several processes ${ }^{17}$. Thus, it is clear that evaluation using imaging methods is fundamentally important for postoperative follow-up for such patients ${ }^{18-19}$, and this may contribute towards elucidating the diagnosis and treatment for the complications.

The application of cholangiopancreatography by means of magnetic resonance (CPMR) for diagnosing biliary complications following OLT began at the end of the 1990s, and there are still only a few reports on its utilization for this purpose ${ }^{18-23}$. The initial use of CPMR was accompanied by controversy regarding the capacity of this method for detecting stenosing lesions in bile ducts without significant dilatation. Moreover, changes in surgeons' preferences regarding the surgical technique most utilized for reconstruction of the bile duct led to loss of the access via a Kehr drain for direct cholangiography, which made early detection of biliary complications difficult.

These factors led us to devise this project, with the aim of evaluating the efficacy of CPMR for detecting biliary complications in patients who underwent OLT from cadaver donors.

\section{Methods}

Retrospective CPMR analysis was performed on 24 patients who had undergone OLT from a cadaver donor at Federal University of São Paulo. The study consisted of 28 examinations, since four patients underwent CPMR twice during their postoperative follow-up, with a minimum interval of six months between them, such that they were therefore considered to be independent examinations. These examinations were carried out between September 2000 and March 2005.

The study protocol was analyzed and granted approval by the Ethics Committee of Federal University of São Paulo.

Indications for examinations were made at the discretion of the clinical team that was attending this group of patients. They were based on suspicions of possible biliary complications, with or without concomitant abnormalities on laboratory tests.
The inclusion criteria for the study were the presence of a correlation with complementary endoscopic retrograde cholangiopancreatography (ERCP) or surgery, in the cases of CPMR presenting abnormalities, or clinical-laboratory follow-up of at least three months in cases of normal CPMR results.

The study group was formed by fifteen men and nine women aged between 11 and 66 years (mean: 40 years; median 42 years). The diseases or associations of diseases that resulted in liver transplantation were hepatitis $C(n=12)$, Wilson's disease $(n=2)$, cirrhosis due to alcohol $(n=1)$, autoimmune hepatitis $(n=1)$, bile duct atresia $(n=1)$, primary sclerosing cholangitis $(n=1)$ or associations of hepatitis $\mathrm{C}$, alcoholism and hepatocarcinoma $(\mathrm{n}=1)$, hemochromatosis and hepatocarcinoma $(\mathrm{n}=1)$, hepatitis $\mathrm{C}$ and hepatocarcinoma $(n=1)$ and hepatitis $C$ and alcoholism $(n=1)$. In two patients, the etiology was not determined (cryptogenic cirrhosis).

The type of bile duct anastomosis present in the analyses from the 28 tests was choledococholedocostomy (duct-duct) without bile drainage in 21 cases and biliodigestive derivation in seven cases. The time interval between the transplantation and performing the examinations ranged from 15 days to 44 months (mean of 8.8 months).

Information was collected with regard to serum values of aspartate aminotransferase (AST), alanine aminotransferase (ALT), alkaline phosphatase (ALP), gamma glutamyl transpeptidase (GGT), total bilirubin (BT) and direct bilirubin (BD), at the time of the examination and during the subsequent three months.

The ERCP examinations of patients who underwent this after CPMR were reanalyzed, and the findings from patients who underwent surgical reintervention were noted. All the patients with abnormalities seen on CPMR underwent ERCP and/or surgery. True negatives were considered to be the cases of negative CPMR with normal biochemical parameters over three months of follow-up, or with abnormal parameters that were secondary to a different etiology that was defined by other examinations or by biopsy.

The examinations were performed on Siemens' Magnetom Impact model $(n=25)$ and Magnetom Sonata model $(n=3)$. Both of these operated with high magnetic fields (1.0 and 1.5 Tesla, respectively), with gradients of $23 \mathrm{mT} / \mathrm{m}$ (Impact) and $40 \mathrm{mT} / \mathrm{m}$ (Sonata). A phased array body coil was used for signal transmission and reception.

\section{Examination technique}

The examinations were performed in accordance with the institution CPMR protocol, with the patients in dorsal decubitus. The sequences carried out are described in the following:

True FISP coronal sequence (TR approx. $6 \mathrm{~ms}$; TE 2.8 ms; flip angle $80^{\circ}$ ), Thick-slab single-shot fast spin echo sequence (4500/940; echo train 240, matrix 360x512, collimation $50 \mathrm{~mm}$, acquisition time 4 seconds), in the coronal-sagittal plane, with rotation in $10^{\circ}$ increments; HASTE sequence (effective TE 96-110; echo train 128, matrix $218 \times 512$, thickness $5 \mathrm{~mm}$ without gap; acquisition time 20 seconds) in the most appropriate oblique coronal plane, which was selected on the basis of the preceding sequence, and in the transversal plane, to reach the level of the bile duct anastomosis.

The field of view (FOV) utilized was $28-35 \mathrm{~cm}$, depending on the patient's size. Saturation bands were positioned adjacent to 
the region of interest, and fat saturation was used in all the sequences. All the sequences were obtained during respiratory pauses. No fasting was undertaken prior to the examination, not was oral contrast or any antiperistaltic agent administered prior to the examination. The thin-section sequences were reconstructed using the MIP technique (maximum intensity projection).

\section{Image analysis}

The images were analyzed independently by two examiners, who were medical radiologists with at least three years of experience in the field. They were unaware of any of the clinical, laboratory or surgical information, or of any other examinations. However, the examiners were told in advance which type of anastomosis had been used in the bile duct reconstruction of the transplantation.

To evaluate the intraobserver concordance, the images were analyzed by the same doctors at least 30 days after the first analysis, in random order. The parameters utilized were: Adequate viewing of the first-order intrahepatic bile ducts, the donor's extrahepatic bile duct, the receiver's extrahepatic bile duct (in cases of duct-to-duct common bile duct anastomosis) and the bile duct anastomosis. The grading system used was: excellent viewing (complete viewing); good (viewing $>90 \%$ ); reasonable (viewing $<90 \%$ ) or absent (not viewed); Dilatation of the intra or extrahepatic bile ducts was defined as present when their diameters were greater than 2 and $7 \mathrm{~mm}$, respectively; Stenosis of the bile duct was defined as a focal narrowing or focal absence of signal from the bile duct in relation to the segments above and below this point that was deemed by the examiner to be a potential cause of obstruction of the bile flow.
The images from the ERCP examinations were analyzed by a third examiner who had experience in interpreting ERCP. The following parameters were used: Dilatation of the intra or extrahepatic bile ducts was defined as present when their diameters were greater than 3 and $8 \mathrm{~mm}$, respectively; Stenosis of the bile duct was defined as a focal narrowing of the bile duct in relation to the segments above and below this point, causing complete obstruction or resistance to the passage of contrast, which was deemed to be relevant as a potential cause of biochemical alterations.

\section{Statistical analysis}

In the statistical analysis, the intra and interobserver concordance was evaluated by means of the Kappa test. After performing comparative analysis between the CPMR and the combination of ERCP/surgery/evolutive control (which was taken to be the gold standard), the sensitivity, specificity, positive predictive value (PPV) and negative predictive value (NPV) of the CPMR were determined, and also the prevalence rates of biliary complications, false positives and false negatives were determined. Subsequently, the groups with and without biliary complications were compared with regard to laboratory test results, by means of the non-parametric Mann-Whitney test.

\section{Results}

\section{Evaluation of biliary abnormalities}

Among the 28 images analyzed, ten abnormalities were found: seven cases of stenosis of the bile duct anastomosis (Figure 1).
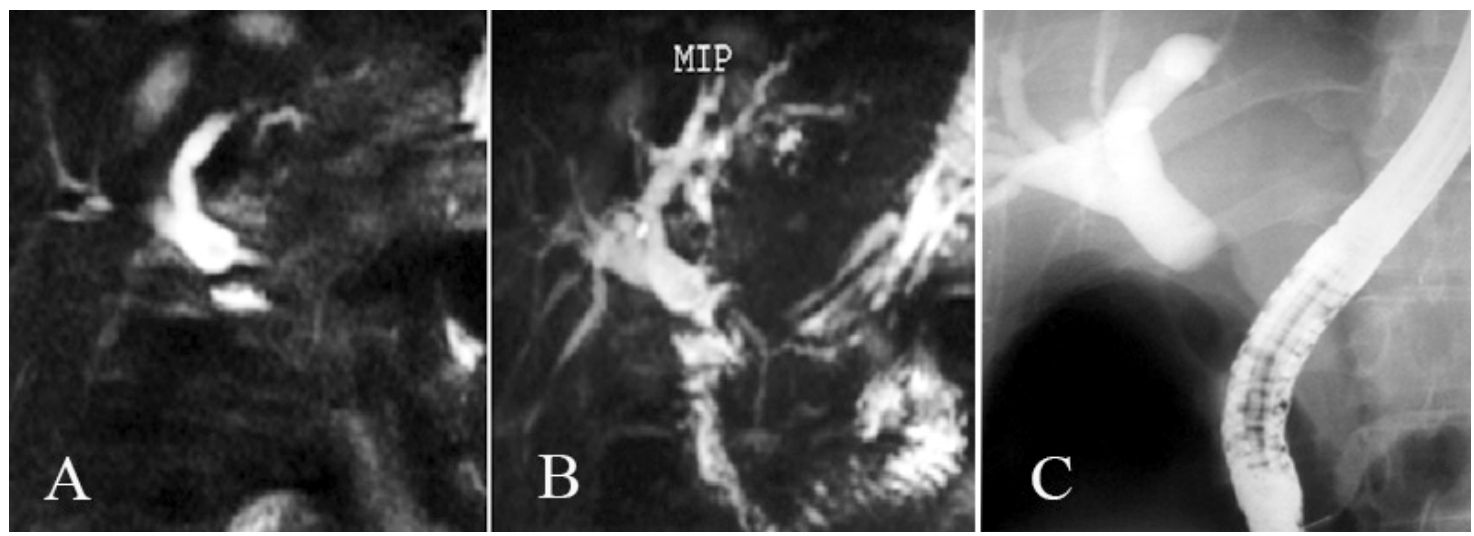

FIGURE 1 - (A) Original image from the HASTE sequence, showing abrupt tapering of the extrahepatic bile duct in the region of the duct-to-duct common bile duct anastomosis, which was associated with upstream dilatation of the bile duct. (B) The same appearance was seen in the MIP reconstruction in the same patient. (C) ERCP imaging confirmed the stenosis of the extrahepatic bile duct in the region of the duct-to-duct common bile duct anastomosis, which was associated with upstream dilatation of the bile duct

Two cases of perihepatic accumulations, in two patients who also presented bile duct stenosis; and one incidental finding of a hepatic lesion that was subsequently confirmed as an abscess. Of these, only seven anastomotic stenosis were considered to be biliary complications.
The final consensus from the analysis, between the two observers, was that seven suspected cases of stenosis of the bile duct anastomosis were shown by CPMR. Six of the seven cases were confirmed by means of ERCP or surgery, and in one case the abnormality seen by means of CPMR was considered to be a false positive (Figure 2). 

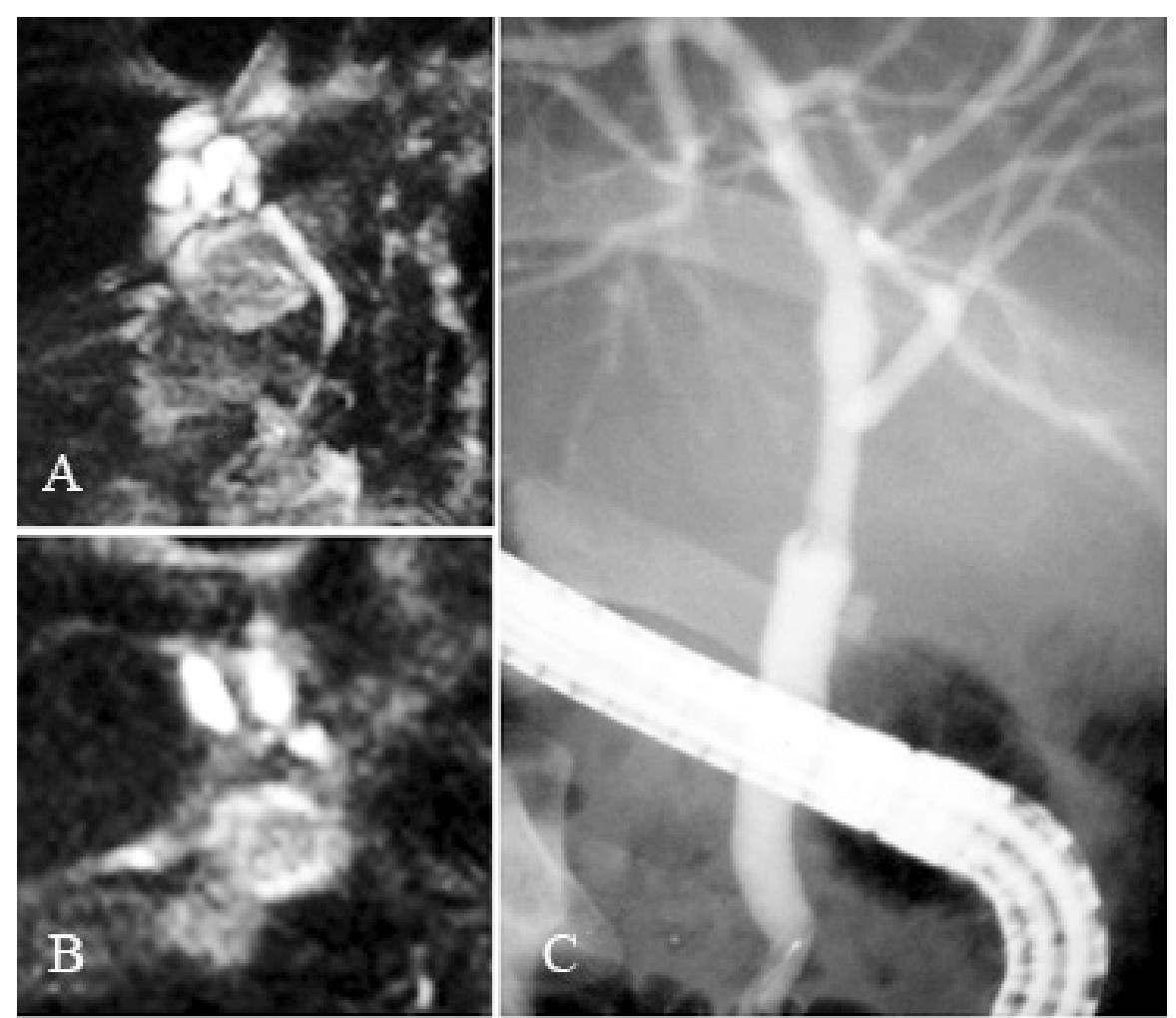

FIGURE 2 - (A) MIP reconstruction of the CPMR sequence and (B) one of the original images from the same examination, which were interpreted as stenosis of the duct-toduct common bile duct anastomosis. (C) ERCP image from the same patient, without evidence of stenosis, noting only slight disproportion between the duct calibers of the donor and receiver (larger caliber)

Among the 21 cases that were considered normal by CPMR, 15 had clinical and laboratory evolution without any evidence of biliary complications, for at least three months subsequent to the examination. In six patients who presented laboratory abnormalities during this follow-up period, alternative diagnoses were confirmed by means of liver biopsy: three were cases of rejection and three were recurrences of viral infection.

With these data, the prevalence rates obtained were $21.43 \%$ for biliary complications, zero for false negatives and $4.55 \%$ for false positives. CPMR presented $100 \%$ sensitivity, $95.45 \%$ specificity, $85.71 \%$ positive predictive value and $100 \%$ negative predictive value. These data are shown in Table 1.

There were no statistically significant differences in the laboratory test results at the time of the CPMR examination, between the groups with biliary complications $(n=6)$ and without biliary complications $(n=22)$. In other words, these tests did not make it possible to differentiate between the two groups.

Comparison of the data obtained by the different observers and at different times, in relation to detecting biliary abnormalities, gave a Kappa index of 0.90 for detecting anastomotic stenosis and 1.00 for the other parameters evaluated, as shown in Tables 2 and 3 , respectively, thus reflecting almost perfect concordance for these evaluations in the two analyses performed.
TABLE 1 - Analysis of the efficacy of CPMR for detecting biliary abnormalities, in comparison with the combination of ERCP, surgery and clinical-laboratory evolution, among patients who had undergone orthotopic liver transplantation

\begin{tabular}{lccc}
\hline \hline \multicolumn{3}{c}{ ERCP / SURGERY / EVOLUTION } \\
\hline \hline CPMR & + & - & Total \\
\hline \hline+ & 6 & 1 & 7 \\
- & 0 & 21 & 21 \\
Total & 6 & 22 & 28 \\
\hline \hline & & \\
Sensitivity: & & 1.0000 \\
Specificity: & & 0.9545 \\
Positive predictive value: & 0.8571 \\
Negative predictive value: & 1.0000 \\
Prevalence rate for biliary complications: & 0.2143 \\
False negative rate: & 0.0000 \\
False positive rate: & 0.0455 \\
\hline
\end{tabular}

CPMR - cholangiopancreatography by means of magnetic resonance ERCP - endoscopic retrograde cholangiopancreatography 
TABLE 2 - Kappa index (k) for evaluating the interobserver concordance in detecting abnormalities in the structures studied, in two analyses

\begin{tabular}{lcc}
\hline \hline Abnormality & First Kappa (k) analysis & Second Kappa (k) analysis \\
\hline \hline $\begin{array}{l}\text { Stenosis of the bile } \\
\text { duct anastomosis }\end{array}$ & 0.900 & 0.900 \\
$\begin{array}{l}\text { Dilatation of the } \\
\text { IHBD }\end{array}$ & 1.000 & 1.000 \\
$\begin{array}{l}\text { Dilatation of the } \\
\text { EHBD }\end{array}$ & 1.000 & 1.000 \\
$\begin{array}{l}\text { Presence of } \\
\text { gallstones }\end{array}$ & 1.000 & 1.000 \\
$\begin{array}{l}\text { Other } \\
\text { abnormalities }\end{array}$ & 1.000 & 1.000 \\
\hline \hline
\end{tabular}

IHBD - intrahepatic bile duct

EHBD - extrahepatic bile duct

TABLE 3 - Kappa index (k) for evaluating the intraobserver concordance in detecting abnormalities in the structures studied, comparing two analyses at different times

\begin{tabular}{lcc}
\hline \hline Abnormalities & Observer 1 - Kappa (k) & Observer 2 - Kappa (k) \\
\hline \hline $\begin{array}{l}\text { Stenosis of the bile } \\
\text { duct anastomosis }\end{array}$ & 0.900 & 0.900 \\
$\begin{array}{l}\text { Dilatation of the } \\
\text { IHBD }\end{array}$ & 1.000 & 1.000 \\
$\begin{array}{l}\text { Dilatation of the } \\
\text { EHBD }\end{array}$ & 1.000 & 1.000 \\
$\begin{array}{l}\text { Presence of } \\
\text { gallstones }\end{array}$ & 1.000 & 1.000 \\
$\begin{array}{l}\text { Other } \\
\text { abnormalities }\end{array}$ & 1.000 & 1.000 \\
\hline \hline
\end{tabular}

IHBD - intrahepatic bile duct

EHBD - extrahepatic bile duct

\section{Viewing of the bile ducts}

The viewing of the intrahepatic bile ducts was classified as excellent or good in 22 of the 28 examinations $(78.57 \%)$ by observer 1, in both analyses. For observer 2, 24 of the 28 examinations were classified as excellent or good in the first analysis and 23 of the 28 examinations in the second analysis.

The viewing of the hepatic duct of the donor and receiver and of the (duct-to-duct) common bile duct anastomosis was considered to excellent or good by both observers in both of their analyses. The patients with biliodigestive anastomosis were excluded from this analysis.

The results of intraobserver concordance for viewing the bile ducts from each observer at different times are showed respectively in Table 4, and had a substantial degree of concordance for all the values.
TABLE 4 - Kappa index (k) for evaluating the intraobserver concordance for categorizing the degree of viewing of the structures studied, comparing two analyses at different times

\begin{tabular}{lcc}
\hline \hline Structure & Observer 1 - Kappa (k) & Observer 2 - Kappa (k) \\
\hline \hline $\begin{array}{l}\text { Intrahepatic } \\
\text { bile duct }\end{array}$ & 0.804 & 0.724 \\
Donor duct & 0.774 & 0.611 \\
Receiver duct & 0.774 & 0.611 \\
$\begin{array}{l}\text { Bile duct } \\
\text { anastomosis }\end{array}$ & 0.774 & 0.611 \\
\hline \hline
\end{tabular}

\section{Discussion}

The wide spectrum of hepatobiliary complications observed in patients following liver transplantation is a challenge for the medical team responsible. The overlap between the clinical and laboratory manifestations of complications as diverse as graft rejection and stenosis of the bile duct anastomosis implies the need for imaging methods that are capable of aiding in differentiating between such complications.

Within the field of biliary complications, the imaging method that is most widely used is ERCP, because it presents excellent anatomical detailing of the bile duct and allows therapeutic management to be performed during the same procedure. However, its application as a screening method for biliary complications in this group of patients has the implication of having to accept a high rate of normal examinations. Thus, its use cannot be justified in the light of the potential serious complications from the examination ${ }^{24-25}$.

Based on this need for a noninvasive examination method with high sensitivity and good availability, and together with the technological development of magnetic resonance equipment, CPMR emerged in the second half of the 1990s as an alternative for diagnosing biliary complication following OLT ${ }^{18-23,26}$.

Investigating the potential use of CPMR for diagnosing biliary complications was the aim of our study, at a time when its viability as a method for studying bile ducts in patients who had undergone liver transplantation was still incipient and therefore under question. Additionally, as a means of confirming the reproducibility of the method, we included a parameter that had not been evaluated in other studies that we reviewed in the literature: the concordance between evaluations made by the same observer at two different times (intraobserver concordance). This was done in addition to evaluating interobserver concordance.

The prevalence rate for biliary complications in the study group was $21.43 \%$, which was within the range of $10-30 \%$ that has been observed in the studies published on this topic so far ${ }^{1-16}$.

The high sensitivity obtained by CPMR $(100 \%)$ is backed up in other publications ${ }^{18-20,23,26}$. This result may be related to the absence of patients at the earliest postoperative stage, thus excluding bile extravasation from the complications. CPMR has limited capability for detecting this complication, because it detects accumulations without identifying their origin ${ }^{29}$. Nevertheless, for all the patients studied, drains were left in place 
next to the anastomoses and no bile extravasation was detected. The refined surgical technique, with the use of continuous sutures and thin absorbable thread, and also high-magnification glasses, must have contributed towards the absence of this type of complication. Furthermore, arterial thrombosis, which is another factor related to bile extravasation, was observed in only one patient.

It was found only one case with abnormalities seen on CPMR that was not subsequently confirmed. This was a diagnosis of anastomotic stenosis seen on CPMR that was not confirmed by ERCP, thus giving the method specificity of $95.45 \%$, which is compatible with other studies in the literature ${ }^{18-20,23,26}$. After analyzing the images from this case, we had the impression that the observers overvalued the "hour glass" appearance that is sometimes present at the anastomosis location. This does not really represent stenosis but, rather, a slight "physiological" or "expected" constriction that is observed in this type of reconstruction of the bile duct. The positive predictive value of $85.71 \%$ and negative predictive value of $100 \%$ corroborate the efficacy of the method.

Although, because of the characteristics of the study, the analysis of the CPMR images was done in a manner analogous to a prospective study, and the rigorous clinical and laboratory follow-up of the patients after the liver transplantation ensured uniformity of the quality of the data obtained from each patient, the fact that the study was retrospective implies that some points should be taken into consideration.

The indication for the examinations, which was under the responsibility of the clinical team, was not rigorously standardized. This might have resulted in patient selection bias, which could have led to underestimation or overestimation of the prevalence of biliary complications.

Because of the usual rigorous postoperative follow-up for OLT cases, all the patients presenting abnormalities on CPMR were subsequently evaluated by ERCP or surgery, thus ensuring that proof was obtained for this study in all these cases. Likewise, in the cases that were seen to be negative on CPMR, the absence of clinical and laboratory abnormalities was seen to be maintained for at least the next three months, or other conditions were diagnosed that would satisfactorily explain the abnormality seen on laboratory tests, and this allowed secure confirmation of the absence of bile duct abnormalities. This criterion for confirming negative cases was used in several of the more recent studies ${ }^{19,20,23,26}$, because of the tendency not to use bile drains, which makes cholangiographic access difficult.

Our data give emphasis to the difficulties that medical teams face with regard to differentiating between the potential complications following OLT, since we did not find any statistically significant differences between the serum levels of the main liver function markers between the groups with and without biliary complications. The proviso to be made is in relation to the relatively small number of biliary complications in the sample studied $(n=6)$. This would make it difficult to detect statistical significance if the differences were small.

The two observers were able to have an excellent or good view of the structures studied (intrahepatic bile duct, donor duct, anastomosis and receiver duct), in both of their analyses. This high frequency of good viewing was expected and was in agreement with the results from other authors ${ }^{18,26}$, and this reflects the capacity of present-day magnetic resonance apparatus to produce bile duct images of trustworthy diagnostic quality. We adopted the practice of informing the observer regarding the type of bile duct anastomosis that had been used, since the lack of this information could lead to errors in interpreting the findings (such that, in cases of biliodigestive derivation, the remaining part of the receiver duct could be interpreted as the distal bile duct associated with apparent anastomotic stenosis). Having this information available is more in keeping with daily clinical practice.

The credibility of a diagnostic method is grounded in how reproducible it is: high reproducibility favors dissemination of its use. If, on the one hand, obtaining reproducible results does not necessarily imply that they are accurate (considering that the examiners might systematically agree on an error), on the other hand, methods with low reproducibility are not associated with high accuracy ${ }^{27}$. Errors in image diagnostics may derive from four variables: inadequate technique, absence of knowledge or training, error of perception and error of judgment. In our study, we believe that the examination technique was adequate and the variable relating to training was minimized by choosing two examiners with experience in interpreting this type of image. The other two variables (errors of perception and judgment) remained, and these are inherent to any image diagnostic evaluation.

From analysis of the reproducibility of the method, with regard to the ability to view the structures studied, this study obtained a substantial degree of interobserver concordance. It reproduced the numbers found by Ward et al. ${ }^{26}$ It also found substantial or near-perfect intraobserver concordance. Intuitively, the intra-observer concordance tends to be greater than or equal to the interobserver concordance, and this was confirmed by our data.

In evaluating the biliary complications, we obtained almost perfect inter and intraobserver concordance in all the analyses. This high reproducibility might not necessarily be a reflection of the efficaciousness of the method. Nonetheless, because of the high sensitivity and specificity values obtained from correlation with the gold standards that are available (ERCP/ surgery/evolutive control), it is clear that the high reproducibility was accompanied by high accuracy.

Thus, this study has established that CPMR presents high reproducibility in evaluations of biliary complications in patients who underwent OLT, with regard to both intra and interobserver reproducibility.

The addition of conventional and angioresonance sequence to the CPMR protocol expands the range of abnormalities that can be detected by the method, such as vascular complications, abdominal accumulations and abnormalities of the hepatic parenchyma like tumors, abscesses and diffuse diseases. This versatility gives rise to the potential for CPMR to become a "one-stop" examination for post-transplantation patients in some cases, thereby enabling diagnosis of vascular thrombosis, abscesses, recurrent neoplasia and biliary complication ${ }^{30}$. For the clinic requesting the examination and for the patient, the greatest attractive features are its rapidity and efficacy, while for the healthcare system, the advantage is its cost-benefit through eliminating the multiplicity of other examinations requested (ultrasound, computed tomography, ERCP, CTHP (percutaneous transhepatic. cholangiography), angiography and others). 
One disadvantage of CPMR in relation to ERCP is that it does not detect bile extravasation. However, as explained earlier, the fact that bile drains are often not used reduces the incidence of this type of complication in patients who underwent OLT. Recent studies have evaluated CPMR in association with the endovenous contrast medium mangafodipir trisodium (Teslascan ${ }^{\circledR}$, Amersham Health) $)^{34,35}$. This consists of a manganese ion bonded to a vitamin B6 analog, which accumulates in the liver and is excreted through the bile duct. It allows functional and morphological evaluation of the bile duct, with application for detecting extravasation, and the results have been promising ${ }^{29,31}$. One study compared CPMR after intravenous administration of mangafodipir trisodium with conventional CPMR, for evaluating patients who had undergone OLT, and obtained better results with the use of this new contrast ${ }^{32}$.

It has been observed a recent trend in the literature relating to all types of biliary complications (and not just with regard to liver transplantation) for noninvasive examinations to be increasingly indicated, while invasive examinations are reserved for selected cases that are difficult to diagnose, or for therapeutic interventions ${ }^{33}$. The numbers that we have presented fall within this context. If all our patients had undergone ERCP, there would have been 21 examinations with negative results, with the potential risks of morbidity that are inherent to this examination, at a rate of 3 to $5 \% 24,25$

The high CPMR reproducibility obtained in this study is a prime factor in trusting the method, for doctors requesting the examination and for the radiologists themselves. We believe that this study will reinforce the indication of CPMR as the first examination for evaluating suspected biliary complications following orthotopic liver transplantation. Considering that it has high diagnostic sensitivity and is noninvasive, it may serve as the sole diagnostic tool and also as an aid for planning therapeutic interventions using the open surgery route or ERCP.

\section{Conclusions}

The cholangiopancreatography by means of magnetic resonance is an efficacious method for detecting biliary complications following liver transplantation from a cadaver donor.

Evaluation of the bile ducts in patients who underwent liver transplantation from a cadaver donor, using cholangiopancreatography by means of magnetic resonance, has high inter and intraobserver reproducibility.

\section{References}

1. Yao FY, Ferrell L, Bass NM. Liver transplantation for hepatocellular carcinoma: expansion of the tumor size limits does not adversely impact survival. Hepatology. 2001;33(6):1394-403.

2. Annual Report of the U.S. Organ Procurement and Transplantation Network and the Scientific Registry for Transplant Recipients; 2003. Available from URL: http://optn.transplant.hrsa.gov/data/annualReport.asp 3. Starzl TE, Marchioro TL, Vonkaulla KN, Hermann G, Brittain RS, Waddell WR. Homotransplantation of the liver in humans. Surg Gynecol Obstet. 1963;117:659-76.

4. Calne RY, McMaster P, Portmann B, Wall WJ, Williams R. Observations on preservation, bile drainage and rejection in 64 human orthotopic liver allografts. Ann Surg. 1977;186(3):282-90.
5. Starzl TE, Putnam CW, Hansbrough JF, Porter KA, Reid HA. Biliary complications after liver transplantation: with special reference to the biliary cast syndrome and techniques of secondary duct repair. Surgery. 1977;81(2):212-21.

6. Stratta RJ, Wood RP, Langnas AN. Diagnosis and treatment of biliary tract complications after orthotopic liver transplantation. Surgery. 1989;106(4):675-83.

7. Greif F, Bronsther OL, Van Thiel DH. The incidence, timing, and management of biliary tract complications after orthotopic liver transplantation. Ann Surg. 1994;219(1):40-5.

8. Campbell WL, Sheng R, Zajko AB, Abu-Elmagd K, Demetris AJ. Intrahepatic biliary strictures after liver transplantation. Radiology. 1994;191(3):735-40.

9. Theilmann L, Kuppers B, Kadmon M. Biliary tract strictures after orthotopic liver transplantation: diagnosis and management. Endoscopy. 1994;26(6):517-22.

10. Rossi G, Lucianetti A, Gridelli B. Biliary tract complications in 224 orthotopic liver transplantations. Transplant Proc. 1994;26(6):3626-8.

11. O'Connor TP, Lewis WD, Jenkins RL. Biliary tract complications after liver transplantation. Arch Surg. 1995;130(3):312-7.

12. Golling M, von Frankenberg M, Ioannidis P. Impact of biliary reconstruction on postoperative complications and reinterventions in 179 liver transplantations. Transplant Proc. 1998;30(7):3180-1.

13. Turrion VS, Alvira LG, Jimenez M. Management of the biliary complications associated with liver transplantation: 13 years of experience. Transplant Proc. 1999;31(6):2392-3.

14. Lopez-Santamaria M, Martinez L, Hierro L. Late biliary complications in pediatric liver transplantation. J Pediatr Surg. 1999;34(2):316-20.

15. Sawyer RG, Punch JD. Incidence and management of biliary complications after 291 liver transplants following the introduction of transcystic stenting. Transplantation. 1998;66(9):1201-7.

16. Sheng R, Zajko AB, Campbell WL, Abu-Elmagd K. Biliary strictures in hepatic transplants: prevalence and types in patients with primary sclerosing cholangitis vs those with other liver diseases. AJR Am J Roentgenol. 1993;161(2):297-300.

17. Ringe B, Oldhafer K, Bunzendahl H, Bechstein WO, Kotzerke J, Pichlmayr R. Analysis of biliary complications following orthotopic liver transplantation. Transplant Proc. 1989;21(1 Pt 2):2472-6.

18. Evans RA, Raby ND, O'Grady JG. Biliary complications following orthotopic liver transplantation. Clin Radiol. 1990;41(3):190-4.

19. Lerut J, Gordon RD, Iwatsuki S. Biliary tract complications in human orthotopic liver transplantation. Transplantation. 1987;43(1):47-51.

20. Demetris AJ, Jaffe R, Starzl TE. A review of adult and pediatric post-transplant liver pathology. Pathol Annu. 1987;22 (Pt 2):347-86.

21. Fulcher AS, Turner MA. Orthotopic liver transplantation: evaluation with MR cholangiography. Radiology. 1999;211(3):715-22.

22. Laghi A, Pavone P, Catalano C. MR cholangiography of late biliary complications after liver transplantation. AJR Am J Roentgenol. 1999;172(6):1541-6.

23. Boraschi P, Braccini G, Gigoni R. Detection of biliary complications after orthotopic liver transplantation with MR cholangiography. Magn Reson Imaging. 2001;19(8):1097-105.

24. Matar LD, Frazer C, Jeffrey G. Magnetic resonance cholangiopancreatography following liver transplantation. Australas Radiol. 1999;43(3):279-83.

25. Meersschaut V, Mortele KJ, Troisi R. Value of MR cholangiography in the evaluation of postoperative biliary complications following orthotopic liver transplantation. Eur Radiol. 2000;10(10):1576-81.

26. Valls C, Alba E, Cruz M. Biliary complications after liver transplantation: diagnosis with $\mathrm{mr}$ cholangiopancreatography. AJR Am J Roentgenol. 2005;184(3):812-20.

27. Cohen SA, Siegel JH, Kasmin FE. Complications of diagnostic and therapeutic ERCP Abdom Imaging. 1996;21(5):385-94. 
28. Suissa A, Yassin K, Lavy A, Lachter J, Chermech I, Karban A. Outcome and early complications of ERCP: a prospective single center study. Hepatogastroenterology. 2005;52(62):352-5.

29. Ward J, Sheridan MB, Guthrie JA. Bile duct strictures after hepatobiliary surgery: assessment with MR cholangiography. Radiology. 2004;231(1):101-8.

30. Robinson PJ. Radiology's Achilles' heel: error and variation in the interpretation of the Rontgen image. Br J Radiol. 1997;70(839):1085-98. 31. Kundel HL, Polansky M. Measurement of observer agreement. Radiology. 2003;228(2):303-8.

32. Vitellas KM, El-Dieb A, Vaswani KK. Using contrast-enhanced MR cholangiography with IV mangafodipir trisodium (Teslascan) to evaluate bile duct leaks after cholecystectomy: a prospective study of 11 patients. AJR Am J Roentgenol. 2002;179(2):409-16.
33. Pandharipande PV, Lee VS, Morgan GR. Vascular and extravascular complications of liver transplantation: comprehensive evaluation with three-dimensional contrast-enhanced volumetric MR imaging and MR cholangiopancreatography. AJR Am J Roentgenol. 2001;177(5):1101-7.

34. Vitellas KM, El-Dieb A, Vaswani K. Detection of bile duct leaks using MR cholangiography with mangfodipir trisodium (Teslascan). J Comput AssistTomogr. 2001;25(1):102-5.

35. Bridges MD, May GR, Harnois DM. Diagnosing biliary complications of orthotopic liver transplantation with mangafodipir trisodium-enhanced MR cholangiography: comparison with conventional MR cholangiography. AJR Am J Roentgenol. 2004;182(6):1497-504.

Conflict of interest: none

Financial source: none

\section{Correspondence:}

Dr. Marcelo Moura Linhares

R. Pedro de Toledo, 980, 152/153

04039-002 São Paulo - SP Brazil

Phone/Fax: (55 11)5571-6784

marbet@uol.com.br

Received: December 16, 2009

Review: February 10, 2010

Accepted: March 17, 2010

\section{How to cite this article}

Linhares MM, Coelho RDS, Szejnfeld J, Goldman SM, Gonzalez AM, Szejnfeld D, Matos C, Salzedas A, Goldenberg A, Lopes-Filho GJ, Matos D. Evaluation of the efficacy and reproducibility of cholangiopancreatography by magnetic resonance for detecting biliary complications following orthotopic liver transplantation. Acta Cir Bras. [serial on the Internet] 2010 May-Jun;25(3). Available from URL: http://www.scielo.br/acb 